\title{
Treating infants with frigg: linking disease aetiologies, medicinal plant use and care- seeking behaviour in southern Morocco
}

\author{
Irene Teixidor-Toneu ${ }^{1 *}$ D, Gary J. Martin², Rajindra K. Puri ${ }^{3}$, Ahmed Ouhammou ${ }^{4}$ and Julie A. Hawkins ${ }^{1}$
}

\begin{abstract}
Background: Although most Moroccans rely to some extent on traditional medicine, the practice of frigg to treat paediatric ailments by elderly women traditional healers known as ferraggat, has not yet been documented. We describe the role of these specialist healers, document the medicinal plants they use, and evaluate how and why their practice is changing.

Methods: Ethnomedicinal and ethnobotanical data were collected using semi-structured interviews and observations of medical encounters. Information was collected from traditional healers, namely ferraggat, patients, herbalists and public health professionals. Patients' and healers' narratives about traditional medicine were analysed and medicinal plant lists were compiled from healers and herbalists. Plants used were collected, vouchered and deposited in herbaria.
\end{abstract}

Results: Ferragat remain a key health resource to treat infant ailments in the rural High Atlas, because mothers believe only they can treat what are perceived to be illnesses with a supernatural cause. Ferragat possess baraka, or the gift of healing, and treat mainly three folk ailments, taqait, taumist and iqdi, which present symptoms similar to those of ear infections, tonsillitis and gastroenteritis. Seventy plant species were used to treat these ailments, but the emphasis on plants may be a recent substitute for treatments that used primarily wool and blood. This change in materia medica is a shift in the objects of cultural meaningfulness in response to the increasing influence of orthodox Islam and state-sponsored modernisation, including public healthcare and schooling.

Conclusions: Religious and other sociocultural changes are impacting the ways in which ferraggat practice. Treatments based on no-longer accepted symbolic elements have been readily abandoned and substituted by licit remedies, namely medicinal plants, which play a legitimisation role for the practice of frigg. However, beliefs in supernatural ailment aetiologies, as well as lack or difficult access to biomedical alternatives, still underlie the need for specialist traditional healers.

Keywords: Southern Morocco, High Atlas, Marrakech, ferragga, Medicinal plants, Disease aetiologies, Childhood ailments

\footnotetext{
* Correspondence: i.teixidor-toneu@reading.ac.uk

${ }^{1}$ Section of Ecology and Evolutionary Biology (EEB), Harborne Building,

School of Biological Sciences, University of Reading, Whiteknights, Reading

RG6 6AS, UK

Full list of author information is available at the end of the article
} 


\section{Background}

Herbal remedies used in traditional medicine are the primary health care resource in many rural communities around the world [1,2]. Traditional medicine is a dynamic system that encompasses the "knowledge, skills and practices based on the theories, beliefs and experiences indigenous to different cultures that are used to maintain health, as well as to prevent, diagnose, improve or treat physical and mental illness" [3]. The availability of biomedicine (defined here as the medical system based on western scientific principles), often perceived as a symbol of modernity, development and globalization in the non-Western world [4, 5], alters care-seeking behaviour and often displaces traditional medicines [6-8]. However, traditional medicine continues to be used because of its effectiveness, lack of modern medical alternatives, high cost of biomedical services, long distance to public health facilities, cultural preferences or a combination of these factors $[9,10]$.

Moroccans may use traditional and biomedicine simultaneously, and consider them compatible [11]. Moroccan ethnomedicine is itself a pluralistic system, blending Prophetic and Galenic humoral medicine [12]. Since medieval times, indigenous Berber medicine has incorporated aspects of oriental Arabic medicine, as well as Al-Andalusian and Sub-Saharan knowledge [13]. Classification and treatment of illnesses is based on the "hot/cold" dichotomy derived from humoral medicine, but also on personalistic aetiologies such as the evil eye ( $l$ in), sorcery (suhur) or intervention of spirits (jnûn) [12]. Whereas naturalistic causes, those that are physical, chemical or pathological, are more often treated with medicinal plants by herbalists (attar, achaba) and midwifes (qblat), personalistic or supernatural causes are treated ritualistically by holy men and women (cherif, chorfa) or Quran experts (fqih) $[12,14,15]$. However, minor ailments are treated at home by herbal remedies; popular knowledge of medicinal plants is widespread in both rural and urban Morocco (see for example [16-18]). Here we report on traditional healers that practice in southern Morocco called ferraggat that whilst treating ailments caused by supernatural causes, use medicinal plants as their main treatment.

Ferraggat (ferragga in singular) are not midwifes (qblat) but specialize in treating children and women' illnesses. Ferraggat are consulted by lay people of all social backgrounds [19]; they are invariably women, normally elderly, who often use a mix of medicinal plants called frigg in their treatments. The word frigg is also used to refer to the treatment itself. Despite their ubiquity as traditional healers in urban and rural southern Morocco, they have been overlooked by the most important references on Moroccan medical anthropology and ethnobotany $[11,13,20]$. The context in which ferraggat work is one of partial or limited access to public health care. In 2015, there were approximately 19.8 under-five deaths per 1000 live births in Morocco (mortality rate of 27.6) with pneumonia, injuries and diarrhoea as the leading causes of death [21]. Although much effort has been put in Morocco towards establishing a national health system to improve health standards and child mortality has decreased considerably in the last decades, the system still has insufficient human and material resources, an uneven geographic distribution of health coverage in detriment of rural areas, and minimal insurance benefits [22].

Traditional medicines have been considered highly symbolic; thus most elements of medicine are meaningful, and meaning can have physiological effects, triggering biological responses in sick people [23]. Moerman and Jonas [23] argue that meaning plays a key role in understanding effectiveness of traditional medicines, which are used in culture-specific contexts. Cultural constructs of efficacy and concepts about health and illness underlie any physiological response to meaning $[23,24]$. However, phylogenetically related medicinal plants are selected across cultures, suggesting pharmacological efficacy of herbal remedies [25, 26]. Studies identifying medicinal plants are common in the ethnobotanical literature, but few consider the illness explanatory models in which they are used [27, 28]. Nevertheless, there are examples in the literature where medicinal plant use is presented in an ethnographic context and described alongside ceremonial, ritualistic treatments [29-31]. These studies stress that both the experience of illness and its treatments need to be understood in their cultural and social contexts. In the case of Morocco, studies either emphasise botanical identifications of medicinallyused plant species [16, 17] or the links between ailment aetiologies and healthcare seeking behaviour $[11,12,14,32]$.

Given the scarcity of literature describing the ferraggat and their practices, the initial aim of this study was to fill this knowledge gap, understanding how knowledge about frigg is learned and transmitted. We describe the ailments treated by ferraggat from an emic perspective and build a basic explanatory model [28], focusing on the symptoms, known causes, therapies and prognosis. We also aimed to understand the selection of medicinal plants used in frigg, linking the treatment with folk healing specialists, popular explanatory models and care-seeking behaviour, in a sociocultural context of recent modernisation and increasing availability of biomedical resources. 


\section{Study sites}

Morocco neighbours Algeria in the east and north-east and Mauritania in the south and south-east and has Atlantic and Mediterranean coastlines. Four mountain ranges, the Rif, the Middle Atlas, the High Atlas and the Anti-Atlas, form a semi-circle around the coastal and middle plains separating them from the Saharan desert (Fig. 1). This topography and the diversity of biomes found in the country favour botanical diversity, and the mountainous areas are considered biodiversity hot-spots within the Mediterranean [33]. Morocco has been at the cross-roads of ancient trade routes and its current population is the result of several waves of migration from Southern Europe, Arabia and Sub-Saharan Africa mixed with the indigenous North African populations [34].

French colonialism brought Western technology to Morocco at the beginning of the $20^{\text {th }}$ century to promote economic development, impacting agricultural and industrial production methods, and human and veterinary medical care. Economic development continued after independence, especially in urban areas since rural societies were viewed as highly conservative, hindering the strategic modernising goals of the new country [35]. Since the 1970s, the gross national income per person has quadrupled, the life expectancy increased by almost 20 years, the number of births per women decreased from six to two, approximately, and primary school net enrolment now reaches 95\% [36]. The rise of a more orthodox form of Islam and compulsory state schooling are influencing a generational cultural change [37].

The present study was situated in the south of the Atlantic plains and neighbouring montane areas, both in the city of Marrakech and the mountainous areas of the El Haouz province, specifically in the N'Fiss valley in the High Atlas mountains. Marrakech and its metropolitan area now have more than a million inhabitants, many of them migrants from neighbouring rural areas, combining traditional and cosmopolitan lifestyles (Fig. 1). Different medical systems are available in Marrakech; renowned for its traditional healers, there are also modern private medical facilities, and everything in between. The rural communes where we conducted the study are directly south of Marrakech, in the High Atlas mountains (Fig. 1). Most of the population is Ishelhin, the indigenous ethnic group of Southern Morocco, who speak Tashelhit, an Amazigh (or Berber) language. According to a recent census approximately $10 \%$ of men also speak Moroccan Arabic [38] and younger generations are increasingly bilingual because they learn Moroccan and Classic Arabic at school and are more likely to participate in the market economy, where Moroccan Arabic is prevalent. Subsistence agriculture and pastoralism remain the main livelihoods in the High Atlas, contributing to three quarters of the local income [39]. Other income is generated by seasonal labour in urban areas, and specialized local occupations including shop keeping, mining and limited engagement in tourism. Biomedical facilities and resources are scarce: there

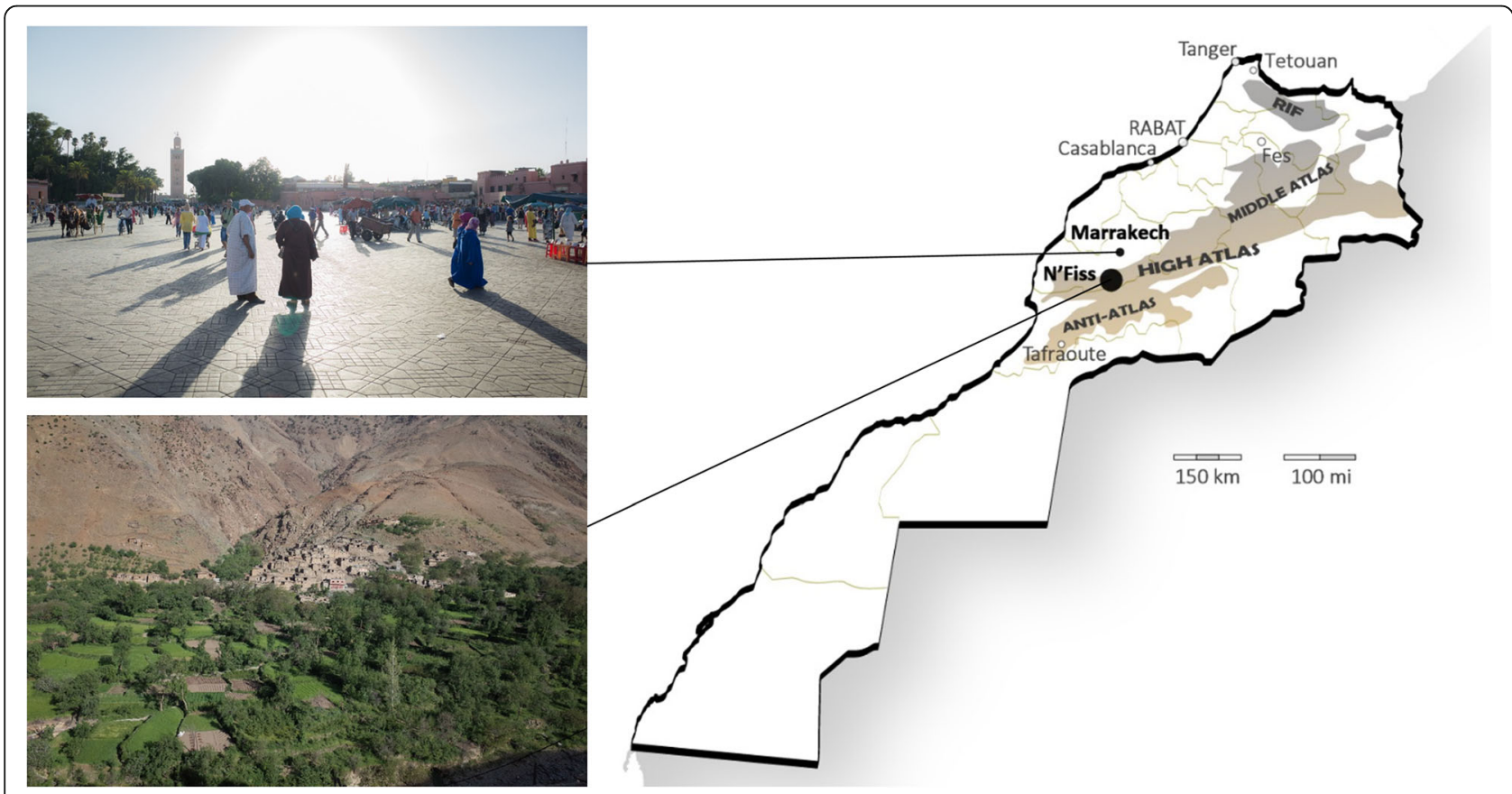

Fig. 1 Map of Morocco and study sites: Marrakech and High Atlas in the N'Fiss valley 
is only one public health centre in each rural commune, for between 5000 and 8000 people [22]. Not all the public health centres have a doctor, and they are usually staffed by non-locals who do not speak Tashelhit, which can pose serious communication issues between staff and their patients.

\section{Methods}

Research was performed following the guidelines of the American Anthropological Association [40] and the code of ethics of the International Society of Ethnobiology [41], and in accordance with the Declaration of Helsinki. Approval from the ethics committee of the School of Biological Sciences, University of Reading, was obtained (Research Ethics Project Submission SBS14-15 05). Before all interactions, prior informed consent was obtained. Unique codes were used to identify informants, whose names were not recorded in the survey to ensure anonymity. Oral permission for publication was obtained from informants. This study was carried out in Marrakech and rural areas of the High Atlas (N'Fiss valley) from February to May 2015. A mixed methods approach was used. All interviews were carried out by the first author.

The rural study focused on the commune of Imegdale, where we interviewed mothers that bring their infants to ferraggat, but it extended to five more rural communes, where some of the ferraggat lived and practised. Nine ferraggat from eight villages in five different rural communes were interviewed. Mothers were interviewed in 11 villages and selected randomly $(n=33)$. Healers $(n=13)$ were selected by asking mothers which ferraggat they normally visit or if they knew of any other women who practised frigg. In Marrakech, ferraggat were contacted through the extended social networks of research assistants. Seven ferraggat were contacted but three did not wish to participate in the study either because of unwillingness to talk while practising (they were the busiest ferraggat we encountered) or distrust. Four ferraggat were interviewed in Marrakech, including two who are originally from the High Atlas. In the N'fiss valley, all available public health professionals $(n=5)$ were interviewed in the health centres of Imegdale and Ouirgane. Since frigg is based on a recipe of medicinal plants and herbalists are the main herb suppliers when ferraggat do not harvest the plants themselves, we also interviewed herbalists $(n=10)$. Herbalists were selected randomly and interviewed in rural market places in the N'Fiss valley (Asni and Talat N'Yakoub) and Marrakech.

Ferragat $(n=13)$ and herbalists $(n=10)$ were asked to list the plants used in frigg (free-listing) [42]. Informants were also asked about where plants are acquired, whether the mixture always has the same ingredients and about criteria for plant selection. A quantitative approach was used to analyse free-lists by calculating use values (UV) for plants in frigg to quantify their cultural importance, following the equation $\mathrm{UV}=\Sigma \mathrm{Uis} / \mathrm{N}$, where $\Sigma$ Uis is the sum of the total number of use reports concerning a given species and $N$ is the total number of informants [43]. We used R v. 3.2 .3 [44] to carry out a non-metric Multidimensional Scaling (MDS) analysis to visualise differences among the plant lists given by informants (isoMDS and metaMDS functions from the MASS and vegan libraries) $[45,46]$, and a t-test to evaluate differences in the number of plants listed by ferraggat and herbalists.

Since very little was known on the frigg subject, qualitative inductive methods where no hypothesis is prespecified were used to elucidate the explanatory models [28], enquiring about the ailments treated, their symptoms, and disease aetiologies. Moreover, ferraggat were questioned about where and from who they had acquired this knowledge and if they had taught it to someone else. The same questions were asked of herbalists $(n=10)$. Moreover, we observed twelve healing sessions with five different ferraggat. We asked staff from public health centres if they knew about frigg and, in the case that they did, they were asked to describe what ferraggat do and to give their opinion on the practice. Mothers were asked if they brought their children to ferraggat when they were sick and why. Interviews were carried out with the assistance of a local Tashelhit-speaking translator in rural areas and a local Moroccan Arabicspeaking translator in urban areas. Qualitative data from in-depth interviews were analysed by cross-checking, summarising and synthesising data collected from interviews to construct a narrative account [47].

Plant specimens were collected in the field with the community's permission, and preferably with the collaboration of an informant, or acquired in the nearest market place and vouchered. Authorisation for plant collection was granted from the University Cadi Ayyad, Marrakech, in accordance with national guidelines and legislation. A. Ouhammou and I. Teixidor-Toneu identified the specimens using the Flore Pratique du Maroc [48]; nomenclature and family assignments follow The Plant List [49]. Vouchers were deposited in the Marrakech Regional Herbarium (Morocco; MARK) and the University of Reading Herbarium (United Kingdom; RNG); permission to export voucher duplicates was obtained from the Faculty of Sciences Semlalia, University Cadi Ayyad, Marrakech.

\section{Results}

Frigg narratives

'Doctors are good, but we need frigg' (Mother in Imegdale) 
Frigg is an important resource for infant healthcare in rural Morocco; 94\% of the rural mothers interviewed seek help from ferraggat when their children are sick. According to the informants, ferraggat deal with ailments that biomedicine is not effective in treating because of their supernatural cause, often associated with sorcery. Mothers from isolated villages also mentioned accessibility and availability as an important reason to prefer traditional medicine. Public health centres are often far away, understaffed or under-resourced, or economically inaccessible, whereas ferraggat live nearby or travel to the patient when necessary. They work " $f i$ sabilillah", for the sake of Allah, without expecting compensation apart from donations. Ferraggat affirmed that they send infants to be treated in the hospital when the ailment is outside of their expertise. All workers of public health centres interviewed were opposed to frigg practise, characterising it as dangerous and backward.

We did not interview mothers in urban areas, but ferraggat do not lack patients in Marrakech. As they explained, mothers often bring their infants when biomedical treatments have proven ineffective. Ferraggat added that they also treat infants from "conservative" mothers who prefer traditional medicine because of their beliefs. Ferraggat in Marrakech are very much like those in the mountains in terms of the settings of the practice (generally their homes) and their availability (working " $f i$ sabilillah"). However, it is worth mentioning the case of a very young ferragga who had an established practise in Marrakech with time schedules and set prices, showing a shift towards professionalization $[50,51]$.

Ailments treated: reported symptoms and perceived causes 'Taumist is a sickness for ferraggat to heal' (Ferragga in Marrakech)

Three main paediatric ailments are treated by ferraggat: taqait, taumist (sarra in Moroccan Arabic) and iqdi (shem in Moroccan Arabic). They can also treat physical development and musculoskeletal problems and women's ailments (not explored here). Taqait literally means "little globule" and the word is normally used to refer to unripe fruits. This word is used because diagnosis is normally made by checking the palate of the infant with the thumb; ferraggat consider the infant has taqait if she feels a little globule on the palate, "like a grain of corn". Infants affected by taqait do not breastfeed, have difficulties in swallowing, can have ear pain (which ferraggat check by touching the area around the ears or softly pulling them) and may also be vomiting. The symptoms of taqait seem to correspond roughly to those of tonsillitis and ear infections. Workers from health centres showed no knowledge of this ailment and it was not mentioned by any ferraggat in Marrakech, so it could be a local folk illness from the High Atlas.
Taumist and iqdi are related, both are associated with a sorcery-related cause. Taumist means "bundle" and it refers to the talismans that people (normally women) carry. These talismans may heal or prevent disease, protect against the Evil Eye, or bring good luck. They are prepared by the fqih, the spiritual religious healer, part of the traditional therapeutic system [20]. They are often made from a paper wrap on which Quranic verses are written and contain salt and seeds of harmel (Peganum harmala). They may contain other plants such as kzbor (Coriandrum sativum), sanouj (Nigella sativa), fijl (Ruta montana) and azuka (Tetraclinis articulata). Babies can fall sick of taumist when around a person carrying a talisman. They are diagnosed with taumist when they have a sunken fontanel, extending to the forehead, the eyes may be rolling up, lethargy may be experienced and the skin has a greenish colour. They may also suffer from diarrhoea, abdominal pain, fever, or a combination of these symptoms. Iqdi literally means "to smell" and it refers to infants "smelling" sorcery or physical bad smells and consequently getting sick. The symptoms of $i q d i$ are a bad skin smell, vomiting, diarrhoea and difficulty with breastfeeding. From a biomedical perspective, these two ailments seem to roughly refer to gastroenteritis, a very common condition in rural areas mostly due to poor diets and inadequate sanitation [52].

These traditional classifications of disease aetiology show both naturalistic and personalistic causes. According to Foster [15], personalistic aetiologies describe ailments caused by "the active, purposeful intervention of an agent who may be human (a witch or sorcerer), nonhuman (a ghost, an ancestor, an evil spirit), or supernatural (a deity or other very powerful being)" (p. 775, italics in the original), whereas naturalistic aetiologies "explain illness in impersonal, systematic terms". Taumist and iqdi are not often the result of purposeful supernatural interventions, being caused by exposure to the harmful "properties" of magical items such as talismans, to which infants are vulnerable. Belief in sorcery as an active cause of adult health problems is widespread across Morocco [11], as well as the belief that infants are vulnerable and passive victims of its harmful effects until the age of two or when they have all their teeth.

\section{Treatment and prognosis}

"Praise be to God, the child will heal" (Ferragga in Marrakech)

Healing sessions start with the creedal statement "bismillah", "in the name of God", and some ferraggat will sprinkle salt on the infant. The Tibb-ul-Nabbi ("Medicine of the Prophet") of Mahmud bin Mohamed alChaghhayni states "Begin with salt, for verily it is remedy for seventy diseases" [53]. Fumigants can also be used at the beginning of the session, especially burning dry 
stems of henna (Lawsonia inermis) or marrut (Marrubium vulgare) close to the infant so they inhale the smoke. Taumist, taqait and iqdi are identified and diagnosed as different ailments but they are generally treated in the same way. Frigg, a blend of dried plants, ground and mixed with olive oil, is used to massage the baby's body. It can also be administrated orally and sometimes as ear and nose drops. Mothers may bring the infant to the ferraggat just once or up to 3 days in a row, depending on the ferraggat's recommendation or on the perceived effectiveness of the treatment. Finally, most ferraggat use qtran rqeq (lit. "thin cade oil"), oils extracted from the roots and branches of various Juniperus species, such as $J$. oxycedrus, and Tetraclinis articulata. A bit of the smoky, strong-smelling oil is put under the baby's nose as well as on top of the head helping "clean out" the "bad smells" and protect the infant from further "smelling". Although sessions usually proceed in this way (for a detailed description see Additional file 1), we interviewed one ferraggat who only used onion, salt and her inherited baraka. We were present in one of her healing sessions that started with the indispensable "bismillah" and sprinkling salt on the infant. Placing the infant on her lap, she took a piece of onion and rubbed it on the infant's head, specifically the top and the sides of the forehead. She finally placed it on the top of the forehead and tied it with a piece of cloth. Ultimately, regardless of the treatment used, all ferraggat attribute healing to God's will.

Perhaps surprisingly, herbalists reported an alternative mode of administration of plants by ferraggat and only two seemed familiar with frigg as reported by ferraggat themselves (Table 1). According to herbalists, plants used by ferraggat are put in a bundle of cotton cloth and infused in hot water. A bit of this water is given to the baby, usually by squeezing some drops from the bundle into the baby's mouth. They call this mixture taktira, literally "drops" in Moroccan Arabic.

Musculoskeletal and development problems are treated by various stretching exercises and thorough massage with either frigg or a cream acquired in the pharmacy (in urban areas), followed by specific bundling sometimes with the use of wooden boards as supports. Qwi, a traditional cauterisation method, is sometimes also used to treat musculoskeletal problems. A burning, dried stem of marrut (Marrubium vulgare) will be used to lightly touch specific points of the baby's body, especially around joints, the abdominal area and the back. Unlike this practise in other countries [54], the stick touches the infant's skin very lightly and it was reported that the treatment never leaves a mark.

\section{Ingredients of frigg}

"If a baby gets sick, I give him herbs" (Ferragga in Talat N'Yakoub)
A high diversity of plants is used in frigg. In total, we inventoried 67 vernacular plant names corresponding to 70 botanical species. Five vernacular names were generic complexes (referring to more than one botanical species) and two others could not be identified. Informants listed $12( \pm 4)$ plants on average, and the number of plants listed by ferraggat or herbalists was not significantly different (t-test, $P$-value $>0.05)$. Fifteen vernacular names were only mentioned by one informant; plants mentioned by two or more informants are listed in Table 2 . Almost half of the plants belong to three families: Lamiaceae (26\%, 17 species), Apiaceae (9\%, six species) and Asteraceae (8\%, five species). Plants with the higher use values are karwiya (Carum carvi; 0.64), timija (Mentha suaveolens; 0.59), azukni (Thymus saturejoides; 0.59), kamun sofi (Ammodaucus leucotrichus; 0.55), rman amrouj (Punica granatum; 0.55), khzema (Lavandula angustifolia; 0.50), za ter (Origanum compactum; 0.45), fliyou (Mentha pulegium; 0.45), uamsa (Foeniculum vulgare; 0.45), lwerd (Rosa sp.; 0.45) and sanouj (Nigella sativa; 0.41). Except for kamun sofi, these are all commonly used plants in the High Atlas [18]. Informants describe medicinal plants used in frigg as "mild", "not bitter" or "not spicy" (maharrsh in Moroccan Arabic); "bitter" plants (harr in Moroccan Arabic) such as shndgora (Ajuga iva) and shih (Artemisia herba-alba) are always used in small doses.

Various opinions about the importance of using plants were found among ferraggat. Some informants thought that correct dosages and the good quality of ingredients were the sole key to a treatment's success. Other ferraggat believed plants are good but the ferragga's touch is more important for the treatment to work. This explanation is in line with what mothers believed about the treatment. Interestingly, eight informants (including three ferraggat) recalled that as recently as one generation ago, fewer plants were used or plants were not used at all. Seven colours of wool yarn and blood from a sheep slaughtered during Eid Al-Adha, one of the two main Islamic festivities, had been used to treat these same infant ailments. This practice is not carried out in the present.

As mentioned above, ferraggat and herbalists often give the medicinal plant mixture different names (frigg versus taktira) and the composition of the mixtures used or sold is also different (Fig. 2; MDS stress factor $=0.19$ ). Mixtures used by urban ferraggat are more similar to those known and sold by herbalists because these two groups have the same medicinal plants available, i.e. those that are traded. Lists from rural ferraggat include many plants that grow in the High Atlas and are not usually traded, such as mkhinza (Dysphania ambrosoides), ifski n'uarras (Cladanthus scariosus) and grzguiel (Lavandula maroccana). However, ferraggat's lists include kzbor 
Table 1 Frigg practise and its transmission per informant. Informants marked with * were not included in the quantitative analysis (MDS)

\begin{tabular}{|c|c|c|c|c|c|c|c|}
\hline $\begin{array}{l}\text { Practitioner } \\
\text { code, location } \\
(U=\text { urban, } R=\text { rural })\end{array}$ & Age & $\begin{array}{l}\text { Source of } \\
\text { knowledge }\end{array}$ & $\begin{array}{l}\text { Knowledge } \\
\text { transmitted } \\
\text { to younger } \\
\text { generations }\end{array}$ & $\begin{array}{l}\text { Years } \\
\text { of } \\
\text { practise }\end{array}$ & $\begin{array}{l}\text { Number } \\
\text { of plants } \\
\text { used }\end{array}$ & Source of plants used & $\begin{array}{l}\text { Mode of preparation; mode } \\
\text { of administration }\end{array}$ \\
\hline Ferragga1, U & $>70$ & $\begin{array}{l}\text { Another ferragga } \\
\text { in Marrakech }\end{array}$ & No & $>40$ & 12 & $\begin{array}{l}\text { Urban herbalists and } \\
\text { harvested from the wild } \\
\text { in the high Atlas }\end{array}$ & $\begin{array}{l}\text { Dried ground plants, mixed with olive } \\
\text { oil; oral ingestion and massage }\end{array}$ \\
\hline Ferragga2, U & $>80$ & $\begin{array}{l}\text { Mother (family } \\
\text { women's lineage) }\end{array}$ & No & $>40$ & 6 & Urban herbalists & $\begin{array}{l}\text { Dried ground plants, mixed with olive } \\
\text { oil; oral ingestion }\end{array}$ \\
\hline Ferragga3, U & $\approx 50$ & Mother & - & 7 & 8 & Urban herbalists & $\begin{array}{l}\text { Dried ground plants, mixed in olive oil; } \\
\text { oral ingestion and massage }\end{array}$ \\
\hline Ferragga4, R & $\approx 50$ & Mother & No & $\approx 10$ & 19 & $\begin{array}{l}\text { Harvested from the wild } \\
\text { and cultivated in home } \\
\text { garden }\end{array}$ & $\begin{array}{l}\text { Dried ground plants, mixed with olive } \\
\text { oil; oral ingestion }\end{array}$ \\
\hline Ferragga5, R & $>70$ & $\begin{array}{l}\text { Another ferragga } \\
\text { in Talat N'Yakoub }\end{array}$ & No & $>40$ & 7 & $\begin{array}{l}\text { Rural herbalists and } \\
\text { harvested from the wild }\end{array}$ & $\begin{array}{l}\text { Decoction in olive oil, filtered; nose } \\
\text { drops and oral ingestion }\end{array}$ \\
\hline Ferragga6, R & $>70$ & $\begin{array}{l}\text { Another ferragga } \\
\text { in Tamslouht }\end{array}$ & - & $>20$ & 9 & $\begin{array}{l}\text { Rural herbalists and } \\
\text { harvested from the wild }\end{array}$ & $\begin{array}{l}\text { Dried ground plants, mixed with olive } \\
\text { oil; oral ingestion }\end{array}$ \\
\hline Ferragga7, R & $\approx 50$ & Mother-in-law & No & $\approx 30$ & 10 & $\begin{array}{l}\text { Rural herbalists and } \\
\text { harvested from the wild }\end{array}$ & $\begin{array}{l}\text { Dried ground plants, mixed with olive } \\
\text { oil; oral ingestion and massage }\end{array}$ \\
\hline Ferragga8* $\mathrm{U}$ & $\approx 50$ & Father & No & $>20$ & 1 & - & Topic \\
\hline Ferragga9, R & $>80$ & Mother & No & $>60$ & 9 & $\begin{array}{l}\text { Rural herbalists and } \\
\text { harvested from the wild }\end{array}$ & $\begin{array}{l}\text { Dried ground plants, mixed with olive } \\
\text { oil; oral ingestion, ear and nose drops, } \\
\text { massage }\end{array}$ \\
\hline Ferragga10, R & $\approx 50$ & $\begin{array}{l}\text { Another ferragga } \\
\text { in Maregha }\end{array}$ & No & 3 & 16 & $\begin{array}{l}\text { Rural herbalists and } \\
\text { harvested from the wild }\end{array}$ & $\begin{array}{l}\text { Dried ground plants, mixed with olive } \\
\text { oil; oral ingestion and massage }\end{array}$ \\
\hline Ferragga11, R & $>80$ & Mother-in-law & No & $\approx 20$ & 16 & $\begin{array}{l}\text { Rural herbalists and } \\
\text { harvested from the wild }\end{array}$ & $\begin{array}{l}\text { Dried ground plants, mixed with olive } \\
\text { oil; massage }\end{array}$ \\
\hline Ferragga12, R & $>70$ & Sister-in-law & No & $>20$ & 12 & Urban herbalists & $\begin{array}{l}\text { Decoction of plants in olive oil, filtered; } \\
\text { oral ingestion and massage }\end{array}$ \\
\hline Ferragga $13^{*}, \mathrm{R}$ & $\approx 60$ & Mother-in-law & Yes & 10 & - & Urban herbalists & $\begin{array}{l}\text { Dried ground plants, mixed with olive } \\
\text { oil; massage }\end{array}$ \\
\hline Herbalist1, U & $\approx 40$ & Father & - & 18 & 15 & Wholesalers & Dried plants infusion; oral ingestion \\
\hline Herbalist2, U & 28 & Father & - & 5 & 7 & Wholesalers & - \\
\hline Herbalist3, U & 85 & $\begin{array}{l}\text { Another herbalist } \\
\text { in Marrakech }\end{array}$ & - & 48 & 13 & Wholesalers & Dried plants infusion; oral ingestion \\
\hline Herbalist4, U & $\approx 40$ & $\begin{array}{l}\text { Father and other } \\
\text { herbalists in } \\
\text { Marrakech }\end{array}$ & - & $>20$ & 19 & Wholesalers & Dried plants infusion; oral ingestion \\
\hline Herbalist5, U & 42 & Father & - & 32 & 22 & Wholesalers & Dried plants infusion; oral ingestion \\
\hline Herbalist6, U & $\approx 50$ & Father & - & $>30$ & 11 & Wholesalers & Dried plants infusion; oral ingestion \\
\hline Herbalist7, U & $\approx 50$ & $\begin{array}{l}\text { Father and } \\
\text { elder brother }\end{array}$ & - & $>30$ & 16 & Wholesalers & $\begin{array}{l}\text { Dried plants infusion or mixed with } \\
\text { olive oil; oral ingestion, ointment for } \\
\text { massage }\end{array}$ \\
\hline Herbalist8, R & $\approx 60$ & $\begin{array}{l}\text { Other herbalist } \\
\text { in Marrakech }\end{array}$ & - & $\approx 40$ & 9 & $\begin{array}{l}\text { Wholesalers and collectors } \\
\text { (harvested from the wild) }\end{array}$ & Dried plants infusion; oral ingestion \\
\hline Herbalist9, R & $\approx 30$ & Grandfather & - & 11 & 9 & Wholesalers & Dried plants infusion; oral ingestion \\
\hline Herbalist10, U & $\approx 50$ & Father & - & $>20$ & 12 & Wholesalers & Dried plants infusion; oral ingestion \\
\hline
\end{tabular}

(Coriandrum sativum), azuka (Tetraclinis articulata) and zfran (Crocus sativus), all traded species not present in herbalists' lists. Although herbalists do not act as healers in this case, their knowledge is not negligible, since all ferraggat rely on at least some traded plants and some acquire ready-made mixtures (Table 1). Differences in herbalists' mixtures compared to those used by ferraggat could also be biased by the herbalists' wish to sell specific plants and lack of knowledge about untraded plants that are common in the High Atlas. 
Table 2 Botanical identification of the plants used in frigg, voucher specimen, number of use reports mentioned by ferraggat (URf) and herbalists (URh), and use value. The phonetic symbol $\uparrow$ has been used to designate the Arabic letter 'ayn ( )

\begin{tabular}{|c|c|c|c|c|c|c|}
\hline Family & Vernaculars & Species (Voucher number) & Plant part used & URf & URh & UV \\
\hline Amaranthaceae & mkhinza & Dysphania ambrosoides (L.) Mosyakin \& Clemants (IME02) & Leaves & 2 & 0 & 0.09 \\
\hline \multirow[t]{6}{*}{ Apiaceae } & habt halawa & Pimpinella anisum L. (MAR40) & Fruits & 1 & 6 & 0.32 \\
\hline & kamun beldi & Cuminum cyminum L. (MAR66) & Fruits & 3 & 0 & 0.14 \\
\hline & kamun sofi & Ammodaucus leuchotricus Coss. (MAR41) & Fruits & 4 & 8 & 0.55 \\
\hline & karwiya & Carum carvi L. (MAR38) & Fruits & 5 & 9 & 0.64 \\
\hline & kzbor & Coriandrum sativum L. (IME42) & Fruits & 4 & 0 & 0.18 \\
\hline & nffa, uamsa & Foeniculum vulgare Mill. (IME27) & Fruits & 2 & 8 & 0.45 \\
\hline \multirow[t]{4}{*}{ Asteraceae } & babunj & $N A(N A)$ & Flowers & 2 & 3 & 0.23 \\
\hline & itzghi, ifski n'uarras & Cladanthus scariosus (Ball) Oberpr. \& Vogt (IME34) & Aerial parts & 3 & 0 & 0.14 \\
\hline & jaidia, ISggaye & NA (MAR36) & Flowers & 0 & 2 & 0.09 \\
\hline & shih & Artemisia herba-alba Asso (IME17) & Aerial parts & 4 & 3 & 0.32 \\
\hline Brassicaceae & habrrchad & Lepidium sativum L. (MAR69_14) & Seeds & 1 & 3 & 0.18 \\
\hline Cactaceae & ajdig n'ouknari, nuwrat Ikarmus & Opuntia ficus-indica (L.) Mill. (IME100) & Flowers & 2 & 4 & 0.27 \\
\hline Cistaceae & $\operatorname{irgl}$ & Cistus salviifolius L. / Cistus creticus L. (IME56 / IME86) & Leaves & 1 & 1 & 0.09 \\
\hline Cupressaceae & azuka, I Ir Sr & Tetraclinis articulata (Vahl) Mast. (IME07) & Leaves & 3 & 0 & 0.14 \\
\hline Fabaceae & helba, tifidas & Trigonella foenum-graecum L. (IME60) & Seeds & 1 & 1 & 0.09 \\
\hline Iridaceae & zasfran & Crocus sativus L. (NA) & Stigmas & 4 & 0 & 0.18 \\
\hline \multirow[t]{11}{*}{ Lamiaceae } & azir, liazir & Rosmarinus officinalis L. (MAR48) & Leaves & 2 & 5 & 0.32 \\
\hline & fliyou & Mentha pulegium L. (IME39) & Leaves & 5 & 5 & 0.45 \\
\hline & grzguiel & Lavandula maroccana Murb. (IME06) & Leaves & 2 & 0 & 0.09 \\
\hline & ifzi, Imrrut & Marrubium vulgare L. (IME24) & Leaves & 4 & 0 & 0.18 \\
\hline & khzema & Lavandula angustifolia Mill. (MAR5) & Leaves, inflores. & 6 & 5 & 0.50 \\
\hline & menta & Clinopodium nepeta (L.) Kuntze (MAR1) & Leaves & 1 & 5 & 0.27 \\
\hline & shndgora & Ajuga iva (L.) Schreb. (IME68) & Leaves, flowers & 1 & 2 & 0.14 \\
\hline & timija & Mentha suaveolens Ehrh. (IME05) & Leaves & 7 & 6 & 0.59 \\
\hline & timzurria, imzurri & Lavandula dentata L. (IME03) & Leaves, inflroes. & 4 & 0 & 0.18 \\
\hline & zStra, azukni & Thymus saturejoides Coss. (IME37) & Leaves, inflores. & 5 & 8 & 0.59 \\
\hline & zaSter & Origanum compactum Benth. (MAR14) & Leaves & 2 & 8 & 0.45 \\
\hline Linaceae & zare St Iktan & Linum sp. (NA) & Seeds & 1 & 2 & 0.14 \\
\hline Lythraceae & rman amrouj & Punica granatum L. (IME61) & Flowers & 4 & 8 & 0.55 \\
\hline \multirow[t]{2}{*}{ Myrtaceae } & knorfel & Syzygium aromaticum (L.) Merr. \& L.M.Perry (MAR49_06) & Fruits & 2 & 1 & 0.14 \\
\hline & riham & Myrtus communis L. (MAR22) & Leaves & 1 & 2 & 0.14 \\
\hline Nitrariaceae & harmel & Peganum harmala L. (IME101) & Seeds & 3 & 1 & 0.18 \\
\hline Pedaliaceae & jnjlan & Sesamum indicum L. (NA) & Seeds & 2 & 1 & 0.14 \\
\hline Piperaceae & ISsfor, bzar & Piper nigrum L. (MAR49_05) & Fruits & 0 & 2 & 0.09 \\
\hline Ranunculaceae & sanouj & Nigella sativa L. (MAR8) & Seeds & 3 & 6 & 0.41 \\
\hline Rosaceae & werd & Rosa sp. (IME105) & Flowers & 4 & 6 & 0.45 \\
\hline Rutaceae & fijil, aurmi & Ruta chalepensis L. / Ruta montana (L.) L. (IME73 / MAR6) & Leaves & 3 & 0 & 0.14 \\
\hline Schisandraceae & badiana & Illicium verum Hook.f. (MAR49_17) & Fruits & 1 & 1 & 0.09 \\
\hline Verbenaceae & louisa & Aloysia citridora Palau (NA) & Leaves & 0 & 3 & 0.14 \\
\hline
\end{tabular}






Fig. 2 Multidimensional Scaling analysis of plant lists given by ferraggat and herbalists (stress factor 0.19)

\section{Transmission of knowledge about frigg}

"I learnt from my mother who learnt from her mother" (Ferragga in Imegdale)

Knowledge entails being aware of facts as well as knowing how to put them into use [55]. In the case of frigg, facts include which plants to use, where to acquire them, which ailments to treat, their symptoms and how to diagnose them, and skills encompass knowing how to prepare the herbal remedies, handle the infant and deliver the treatment. Knowledge about the medicinal plants used in frigg is transmitted orally and most ferraggat had learnt from their mothers, grandmothers or mothers-in-law (vertical and oblique transmission, sensu Cavalli-Sforza and Feldman [56]; Table 1). Others had learnt from another ferragga (horizontal transmission). Herbalists learnt mainly from their fathers $(80 \%$, vertical transmission) and occasionally also from elder herbalists to whom they were apprenticed (oblique transmission; Table 1).

Unlike other folk knowledge about medicinal plants that people learn continuously from childhood to adulthood or need to come in direct contact with natural environments [57], learning about frigg occurs when women are middle aged and already have children. Ferraggat had learnt either from a relative or from a peer. When learning occurs from a relative, women observe and help elder ferraggat practise at home for long periods of time. On the other hand, ferraggat that had learnt from a peer explained that there is actually no teaching on how to become a ferraggat besides a few indications, such as the list of medicinal plants used and how to diagnose. Other ferraggat, herbalists, knowledgeable older women and even pharmacists were mentioned as sources of knowledge about medicinal plants. Only one of them reported she had gone through a period of apprenticeship. Importantly though, in all cases permission and the gift of baraka has to be given from another ferragga for a woman to become a ferragga herself. This gift and transfer of authority is sometimes materialized by a pinch of salt that is physically given, and will be kept and passed on. Only two ferraggat considered this unimportant and placed much more value on the plants themselves. Four ferraggat explained that they became healers unintentionally: when learning how to treat their own infants, they were passed the gift of baraka from another ferragga and thus they accepted the moral obligation to treat other infants if mothers in need approached them.

At the time of this study, only one ferragga had already taught someone else, but this apparent lack of transmission to younger generations is partially misleading. Most ferraggat only started learning and practising when there was the perceived need for it, for example when the village ferragga was dying or moving out, so the ferraggat we interviewed may still pass on their knowledge. Also, mothers that learn how to treat their children without the intention of becoming a ferragga may become healers in the future. However, many of ferraggat explained that 
young people are not interested in learning about traditional medicine, a view that was shared by mothers. When discussing the possible lack of frigg specialists in the future, several informants were of the opinion that ailment-related beliefs will also change so people may just go to the hospital.

\section{Discussion}

Cultural and socioeconomic background are well known factors driving health care seeking behaviour [31, 58-60]. In Morocco, biomedical treatment of illness predominates: a high proportion of patients use only biomedical resources or combine traditional and biomedicine [11, 32]. According to Obermeyer [32], Moroccan women's beliefs and healthcare practices during pregnancy and birth allow a coherent integration of traditional and biomedical practice. As for other folk ailments with personalistic aetiologies [61], including illnesses resulting from the Evil Eye [62], popular explanatory models for taumist and iqdi demand the use of traditional specialists. Ferraggat address illnesses in a context of shared beliefs about health and ailment causality, i.e. the contact of the child with sorcery. They are associated with Baraka, or divine blessing as the gift for healing, so perceived efficacy of frigg may be influenced by cultural constructs of efficacy [20,24] and responses to meaning [25]. Equally important, ferraggat in rural areas have personal relationships with their patients and few time constraints, so psychological aspects of healing can be enhanced, contributing to the perceived efficacy of their therapy $[27,63]$.

Frigg includes a mixture of ritualistic and ethnopharmacological treatments, as is common for other folk ailments with personalistic aetiologies $[29,61]$. In the case of susto, phytochemical activity of oral plant remedies has been demonstrated [64] and yet these are not the most common form of treatment and are often used externally [29]. Species-rich mixtures such as frigg may be effective means to treat ailments with multifactorial causes, including gastroenteritis [65], and there is evidence for pharmacological activity for over half of the high use value plants used in frigg [18]. However, narratives about the frigg practice suggest that specific plant species are not as important to achieve healing as the healing hand itself. We evidence recent incorporation of plants into this healing practise, replacing more ritualistic treatments. The shift to plant based remedies used in frigg is probably due to currently popular narratives on plant efficacy and the influence of Islamic reforms. Symbolic remedies such as coloured wools and blood are linked to pre-Islamic beliefs, nowadays considered haram practises forbidden by Islam. Herbal remedies are a currently accepted means of treatment, representing the fusion of nature with science [66], and are acknowledged by religion [53]. The rise of a more orthodox
Islam, enhanced religious education in rural areas and globalisation, are also altering other local beliefs and practises in the High Atlas such as saint worship [67] or women's tattooing (Teixidor-Toneu et al., in prep.). Islam has also been observed to affect the symbolic framework of healing practices in other Muslim countries [30]. Traditional therapeutic systems where traditional healers practice are dynamic, historically contingent, and embedded within social institutions and socioecological processes. Thus, practices and treatments can be influenced by contact with modernity, science and technology, as well as by religious reforms. Although, medicinal plant use as a means of healing is often viewed as the result of indigenous experimentation with the environment over centuries (see for example [57]), there is evidence for rapid change of herbal practises when isolated indigenous groups come in contact with new cultures and plants. For example, the Ese Eja elders testify that in recent memory healers cured without using or ingesting any plants; in this context the adoption of plants represents the acquisition of knowledge, power and agency from "outsiders" [68]. Similarly, Polynesians are thought to have had a limited herbal medicine tradition prior to European contact [69]. The use of mixtures is ubiquitous in the High Atlas and Morocco in general $[13,18]$, and our analysis suggests that mixtures of widely-available plants are easy to adopt and function to legitimise the ferraggat's practice in the context of modernisation and biomedical treatment, by a transference of cultural meaningfulness from currently illicit symbols. Indeed, ritualistic elements from the frigg practice that are accepted by religion, namely the use of salt, are maintained.

Sociocultural changes can result in changing experiences of illness and their explanatory models, and acculturation can lead to their dismissal altogether [70]. Although we did not observe changes in the conceptualisation of the studied culture-specific ailments because of strong beliefs in supernatural ailment aetiologies, schooling and exposure to biomedicine could have an effect of this kind in the near future. School attendance reduces time at home learning about health, or outdoors acquiring empirical ecological knowledge [71, 72] and presents a discourse where village-based knowledge is perceived as backward [73]. This goes hand in hand with the narratives on the supremacy of biomedicine from healthcare professionals, effectively shifting local medical knowledge paradigms. Leonti and Casu [65] predict that changes in explanatory models could reduce the effectiveness of traditional therapies, because their meaning is weakened. Frigg practice altogether could also experience a loss of meaning in future generations, as observed for eghindi, a culture-specific ailment among the Sahrawi [70]. Whether we are documenting a differential change in different aspects of medicinal practice, with disease 
conceptualisation persisting whilst the object of meaning for treatment adapts, should be the focus of future research. This could provide insights into the processes by which traditional medical systems adapt to sociocultural, economic and environmental changes.

\section{Conclusion}

We have presented a current overview of a traditional medical treatment, frigg, a practice not previously reported in the ethnomedical literature, in the context of modernisation and contact with biomedicine. Frigg is used to treat mostly ailments with personalistic causes, and this drives mothers' to seek treatment from traditional healers who practise in a context of shared beliefs on health and illness. The treatment has changed, and biomedicine is currently available, but preference of mothers to visit ferraggat for certain infant ailments persists, as observed for other illnesses in various cultures. Contrary to the widespread view among ethnobotanists that medicinal plant knowledge is archaic and largely based on prolonged experimentation in one's environment, we report that widely available medicinal plants as the core for treatment might be recently adopted. Southern Moroccan women and healers maintain folk conceptualisations of illness, but adapt treatments to match modern ideas, especially those stemming from new religious viewpoints. Use of medicinal plants is historically contingent and may serve to legitimise a treatment which a generation ago relied on apparently more symbolic remedies. This case study provides new insights on the dynamic aspects of traditional medicine and how sociocultural changes impact medicinal plant use, challenging widespread views about medicinal plant use being archaic.

\section{Additional file}

Additional file 1: Detailed description of a frigg session in Marrakech from I.T.'s field journal. (DOCX $15 \mathrm{~kb}$ )

\section{Acknowledgements}

We would like to acknowledge in kind support provided by the Darwin Initiative (Project Number 20-013: Medicinal root trade, plant conservation and local livelihoods in Morocco). Heartfelt thanks to all the people who have participated and contributed to this study, especially Lalla Saadia Bounhir and Hasnaa Benlafkih for all the in depth discussions. Fieldwork in Morocco would have not been possible without the collaboration of Naima Akif, Hamid Ait Baskad, Fadma Ait Iligh, Mohamed El Haouzi, Rachid Jaafari, and Abderrahim Ouarghidi, many thanks to them. Thanks to Yann Andrieu for designing the map of Morocco. We are also thankful to the comments of two anonymous reviewers that helped improve this manuscript.

\section{Funding}

This work has received funding from the European Union's Seventh Framework Programme for research, technological development and demonstration under the grant agreement no. 606895 .

\section{Availability of data and materials}

Herbarium specimens are available in the University of Reading Herbarium (UK, RNG) and in the Marrakech Regional Herbarium (Morocco, MARK). All datasets on which the conclusions of the paper are based are made available in the manuscript.

\section{Authors' contributions}

Author contributions are as follows: IT-T - Conception and design, acquisition of data, plant identification, analysis and interpretation of data; GJM - Conception and design, analysis and interpretation of data; $\mathrm{AO}$ - Plant identification, analysis and interpretation of data; RKP - Analysis and interpretation of data; JAH Analysis and interpretation of data. IT-T drafted the manuscript and all authors revised it critically for important intellectual content. All authors read and approved the final manuscript.

\section{Competing interests \\ The authors declare that they have no competing interests.}

\section{Consent for publication}

Consent for the publication of the study's results was obtained verbally from the research participants, as mentioned in the methods section. A consent form has not been submitted because the manuscript does not include personal details, images or videos of the research participants.

Ethics approval and consent to participate

Ethical approval (name of the ethics committee and reference number) and consent to participate are mentioned in the methods section.

\section{Author details}

${ }^{1}$ Section of Ecology and Evolutionary Biology (EEB), Harborne Building, School of Biological Sciences, University of Reading, Whiteknights, Reading RG6 6AS, UK. ${ }^{2}$ Global Diversity Foundation, Marrakech, Morocco. ${ }^{3}$ Centre for Biocultural Diversity, School of Anthropology and Conservation, University of Kent, Canterbury, Kent CT2 7NR, UK. ${ }^{4}$ Department of Biology, Laboratory of Ecology and Environment, Regional Herbarium MARK, Faculty of Sciences Semlalia, Cadi Ayyad University, PO Box 2390, Marrakech 40001, Morocco.

Received: 31 August 2016 Accepted: 29 November 2016

Published online: 13 January 2017

\section{References}

1. Bannerman RH, Burton J, Wen-Chieh C, editors. Traditional medicine and health care coverage. Geneva: World Health Organisation; 1983.

2. Bellakhdar J. A new look at traditional medicine in Morocco. World Health Forum. 1989;10:193-9.

3. WHO. Traditional medicine. Fact sheet $\mathrm{N}^{\circ} 134.2008$. http://www.who.int/ mediacentre/factsheets/2003/fs134/en/. Accessed 5 May 2014.

4. Wayland $C$. The failure of pharmaceuticals and the power of plants: medicinal discourse as a critique of modernity in the Amazon. Soc Sci Med. 2004;58:2409-19.

5. Whyte SR, Van der Geest S, Hardon A. Social lives of medicines. Cambridge: Cambridge University Press; 2007

6. Quinlan MB, Quinlan RJ. Modernization and medicinal plant knowledge in a Caribbean horticultural village. Med Anthrop Q. 2007;21:169-92

7. Vandebroek I, Calewaert J, De Jonckheere S, Sanca S, Semo L, Van Damme P, Van Puyvelde L, De Kimpe N. Use of medicinal plants and pharmaceuticals by indigenous communities in the Bolivian Andes and Amazon. Bull World Health Organ. 2004;82:243-50.

8. Saethre EJ. Conflicting traditions, concurrent treatment: medical pluralism in remote aboriginal Australia. Oceania. 2007;77:95-110.

9. Baker P, Gesler W. Physical access to primary health care in Andean Bolivia. Soc Sci Med. 2000;50:1177-88.

10. Thomas E. Medicinal plant use as an adaptive strategy in the Bolivian Andes: evidence from a Quechua community in Apillapampa. In: Lozny LR, editor. Continuity and change in cultural adaptation to mountain environments. New York: Springer Science+Business Media; 2013. p. 275-301.

11. Mateo Dieste JL. Salud y ritual en Marruecos: concepciones del cuerpo y prácticas de curación. Alborán: Bellaterra; 2010.

12. Greenwood B. Cold or spirits? Choice and ambiguity in Morocco's pluralistic medical system. Soc Sci Med. 1981;15:219-35. 
13. Bellakhdar J. La pharmacopée marocaine traditionnelle. Médecine arabe ancienne et savoirs populaires. Paris: Ibis Press; 1997.

14. Baker J. The rise of female healers in the Middle Atlas, Morocco. Soc Sci Med. 1992;35:819-29.

15. Foster GM. Disease etiologies in non-western medical systems. Am Anthropol. 1976;78:773-82.

16. El-Hilaly J, Hmammouchi M, Lyoussi B. Ethnobotanical studies and economic evaluation of medicinal plants in Taounate province (Northern Morocco). J Ethnopharmacol. 2003;86:149-58.

17. Fakchich J, Elachouri M. Ethnobotanical survey of medicinal plants used by people in Oriental Morocco to manage various ailments. J Ethnopharmacol. 2014; 154:76-87.

18. Teixidor-Toneu I, Martin GJ, Ouhammou A, Puri RK, Hawkins JA. An ethnomedicinal survey of a Tashelhit-speaking community in the High Atlas, Morocco. J Ethnopharmacol. 2016;188:96-110.

19. Sajiai H, Bouskraoui M. Enquête prospective sur la "ferraga" dans la région de Marrakech. Article de thèse. Faculté de Médecine et de Pharmacie. Marrakech: Université Cadi Ayyad; 2007.

20. Bakker J. The lasting virtue of traditional healing. Amsterdam: VU University Press; 1993

21. UNICEF. UNICEF data: Monitoring the situation of children and women. 2015. http://data.unicef.org/child-mortality/under-five.html Accessed 14 June 2016.

22. Semlali H. Morocco case study: Health care environments in Morocco. International Council of Nurses, International Pharmaceutical Federation, World Dental Federation, World Medical Association, International Hospita Federation, World Confederation for Physical Therapy. 2010. http://www. who.int/workforcealliance/knowledge/PPE_Morocco_CaseStudy.pdf Accessed 20 June 2016.

23. Moerman DE, Jonas WB. Deconstructing the placebo effect and finding the meaning response. Ann Intern Med. 2002;136:471-6.

24. Etkin NL. Cultural constructions of efficacy. In: Whyte R, Van der Geest S, editors. The context of medicines in developing countries. Hingham: Kluwer; 1988. p. 299-326.

25. Moerman DE. Symbols and selectivity: a statistical analysis of Native American medical ethnobotany. J Ethnopharmacol. 1979;1:111-9.

26. Saslis-Lagoudakis CH, Savolainen V, Williamson EM, Forest F, Wagstaff SJ, Baral SR, Watson MF, Pendry CA, Hawkins JA. Phylogenies reveal predictive power of traditional medicine in bioprospecting. PNAS. 2012;109:15835-40.

27. Waldstein A, Adams C. The interface between medical anthropology and medical ethnobiology. J Roy Anthrop Inst (NS). 2006;12:S95-118.

28. Kleinman A. Concepts and a model for the comparison of medical systems as cultural systems. Soc Sci Med. 1978;12:85-93.

29. Thomas E, Vandebroek I, Van Damme P, Semo L, Noza Z. Susto etiology and treatment according to Bolivian Trinitario People: A "masters of the animal species" phenomenon. Med Anthr Q. 2009:23:298-319.

30. Frazão-Moreira A. The symbolic efficacy of medicinal plants: practices, knowledge, and religious beliefs amongst the Nalu healers of Guinea-Bissau. J Ethnobiol Ethnomed. 2016;12:24.

31. Paulos B, Fenta TG, Bisrat D, Asres K. Health seeking behavior and use of medicinal plants among the Hamer ethnic group, South Omo zone, southwestern Ethiopia. J Ethnobiol Ethnomed. 2016:12:44.

32. Obermeyer CM. Pluralism and pragmatism: Knowledge and practice of birth in Morocco. Med Anthrop O. 2000;14:180-201.

33. Medail F, Quezel P. Hot-spots analysis for conservation of plant biodiversity in the Mediterranean basin. Ann Missouri Bot Gard. 1997:84:112-27.

34. Henn BM, Botigué LR, Gravel S, Wang W, Brisbin A, Byrnes JK, Fadhlaoui-Zid K, Zalloua PA, Moreno-Estrada A, Bertranpetit J, Bustamante CD, Comas D. Genomic Ancestry of North Africans Supports Back-to-Africa Migrations. PLoS Genet. 2012. doi:10.1371/journal.pgen.1002397.

35. Lagnaoui A. Aux frontières de la tradition marocaine. Casablanca: Editions Toubkal; 1999

36. Open Data of the Moroccan Administration. http://data.gov.ma/fr (2016) Accessed 22 Sept 2016.

37. Terem E. Old Texts, New Practices: Islamic Reform in Modern Morocco. Stanford: Stanford University Press; 2014

38. Haut Commissariat au Plan. Recensement général de la population et de I'habitat. 2014. http://rgph2014.hcp.ma/Resultat-du-Recensementgeneral-de-la-population-et-de-l-habitat-2004_a59.html. Accessed 15 July 2015.
39. Bellaoui A. Les pays de I-Adrar-n-Dern. Etude géographique du Haut Atlas de Marrakech. Ph.D dissertation. Tours: Université de Tours, Département de Géographie; 1989.

40. American Anthropological Association. Statement on ethics: principles of responsibility. 2012. http://ethics.americananthro.org/category/statement/.

41. International Society of Ethnobiology. ISE Code of Ethics. 2006 with 2008 additions. http://www.ethnobiology.net/code-of-ethics/ Accessed 10 Sept 2014

42. Bernard HR. Research methods in anthropology - qualitative and quantitative approaches. 5th ed. New York: Altamira Press; 2006.

43. Tardio J, Pardo-de-Santayana M. Cultural importance indices: a comparative analysis based on the useful wild plants of Southern Cantabria (Northern Spain). Econ Bot. 2008:62:24-39.

44. R Core Team. R: A language and environment for statistical computing. $\mathrm{R}$ Foundation for Statistical Computing. https://www.R-project.org/ (2015). Accessed 15 July 2014

45. Venables WN, Ripley BD. Modern Applied Statistics with S. 4th ed. New York: Springer; 2002.

46. Oksanen J, Kindt R, Legendre P, O'Hara B, Simpson GL, Solymos P, Stevens MHH, Wagner $\mathrm{H}$. The vegan package. 2008. http://vegan.r-forge.r-project.org/ Accessed 14 April 2016

47. Newing H, Eagle CM, Puri RK, Watson CW. Conducting research in conservation: a social science perspective. London: Routledge; 2011.

48. Fennane M, Ibn Tattou M, Mathez J, Ouyahya A, El Oualidi J, editors. Flore pratique du Maroc: Manuel de détermination des plantes vasculaires. Vols. 1-3. Rabat: Institut Scientifique, Université Mohammed $V_{i}$ 1999, 2007, 2014.

49. TPL. The Plant List, a working list of all known plant species. Version 1.1. 2013 http://www.theplantlist.org/ Accessed 15 Sept 2015

50. Flint K. Competition, race, and professionalization: African healers and white medical practitoners in Natal, South Africa in the early twentieth century. Soc Hist Med. 2001;14:199-221.

51. Pordié L, Simon E. Que sont les guérisseurs devenus? In: Pordié L, Simon E, editors. Les nouveaux guérisseurs: biographies de thérapeutes au temps de la globalisation. Paris: Editions de l'École des Hautes Études en Sciences Sociales; 2013. p. 9-35.

52. De Wet H, Nkwanyanaa WN, Van Vuuren SF. Medicinal plants used for the treatment of diarrhoea in nothern Maputaland, KwaZulu-Natal Province, South Africa. J Ethnopharmacol. 2010;130:284-9.

53. Elgood C. Tibb-ul-Nabbi or medicine of the Prophet. Osiris. 1962;14:33-192.

54. Ghazanfar S. Wasm: a traditional method of healing by cauterisation. J Ethnopharmacol. 1995;47:125-8.

55. Puri RK. Transmitting Penan basketry knowledge and practice. In: Ellen R, Lycett SJ, Johns SE, editors. Understanding cultural transmission in anthropology. Oxford: Berghahn Books; 2013. p. 266-99.

56. Cavalli-Sforza L, Feldman M. Cultural transmission and evolution: a quantitative approach. Princeton: Princeton University Press; 1981.

57. Reyes-García V, Broesch J, Calvet-Mir L, Fuentes-Peláez N, McDade TW, Parsa S, Tanner S, Huanca T, Leonard WR, Martínez-Rodríguez MR, TAPS Bolivian Study Team. Cultural transmission of ethnobotanical knowledge and skills: an empirical analysis from an Amerindian society. Evol Hum Behav. 2009;30:274-85

58. Nnko S, Bukenya D, Kavishe BB, Biraro E, Peck R, Kapiga S, Brosskurth H, Seeley J. Chronic diseases in North-West Tanzania and Southern Uganda. Public perceptions of terminologies, aetiologies, symptoms and preferred management. Plos One. 2015. doi:10.1371/journal.pone.0142194.

59. File K, McLaws ML. Ni-Vanuatu health-seeking practices for general health and childhood diarrheal illness: results from a qualitative methods study. BMC Res Notes. 2015. doi:10.1186/s13104-015-1151-7.

60. Granich R, Cantwell MF, Long K, Maldonado Y, Parsonnet J. Patterns of health seeking behavior during episodes of childhood diarrhea: a case study of Tezotil-speaking Mayans in the highlands of Chiapas, Mexico. Soc Sci Med. 1999;48:489-95.

61. Berlin EA, Berlin B. Medical ethnobilogy of the highland Maya of Chiapas, Mexico: The gastrointestinal diseases. Princeton: Princeton Legacy Library; 1996.

62. Weller SC, Baer RD, Garcia de Alba Garcia J, Glazer M, Trotter II R, Salcedo Roncha AL, Klein RE, Pachter LM. Variation and persistence in Latin American beliefs about Evil Eye. Cross-Cult Res. 2015;49:174-203.

63. Kleinman A, Van der Geest S. 'Care' in health care. Remarking the moral world of medicine. Medische Anthropologie. 2009;21:159-68. 
64. Bourbonnais-Spear N, Awad R, Merali Z, Maquin P, Cal V, Arnason JT. Ethnopharmacological investigation of plants used to treat susto, a folk illness. J Ethnopharmacol. 2007;91:189-208.

65. Leonti M, Casu L. Traditional medicines and globalization: current and future perspectives in ethnopharmacology. Front Pharmacol. 2013;4:92.

66. Schultes RE, Raffauf RF. The healing forest. Medicinal and toxic plants of the Northwest Amazonia. Portland: Dioscorides Press; 1990.

67. Dominguez $P$, Benessaiah N. Multi-agentive transformations of rural livelihoods in mountain ICCAs: the case of the decline of community-based management of natural resources in the Mesioui agdals (Morocco). Quat Int. 2015; in press.

68. Alexaides MN, Peluso DM. Plants 'of the ancestors', plants 'of the outsiders': Ese Eja history, migration and medicinal plants. In: Alexaides MN, editor. Mobility and migration in indigenous Amazonia: contemporary ethnoecological perspecitves. Oxford: Berghahn; 2009. p. 220-48.

69. Palmer CT. The inclusion of recently introduced plants in the Hawaiian ethnopharmacopoeia. Econ Bot. 2004;58:S280-93.

70. Volpato G, Waldstein A. Eghindi among Sahrawi refugees of Western Sahara. Med Anthrop. 2014;33:160-77.

71. Glewwe P. Why does mother's schooling raise child health in developing countries? Evidence from Morocco. J Hum Resour. 1999;34:124-59.

72. Reyes-García V, Kightley E, Ruiz-Mallén I, Fuentes-Peláez N, Demps K, Huanca T, Martínez-Rodríguez MR. Schooling and local environmental knowledge: Do they complement or substitute each other? Inter J Educ Dev. 2010;30:305-13.

73. Pigg SL. Inventing social categories through place: social representations and development in Nepal. Comp Stud Soc Hist. 1992;34:491-513.

\section{Submit your next manuscript to BioMed Central and we will help you at every step:}

- We accept pre-submission inquiries

- Our selector tool helps you to find the most relevant journal

- We provide round the clock customer support

- Convenient online submission

- Thorough peer review

- Inclusion in PubMed and all major indexing services

- Maximum visibility for your research

Submit your manuscript at www.biomedcentral.com/submit 